\title{
Acute but Not Chronic Tempol Treatment Increases Ischemic and Reperfusion Ventricular Arrhythmias in Open-Chest Rats
}

\author{
J. NECKÁŘ, B. OŠŤÁDAL, F. KOLÁř \\ Institute of Physiology, Academy of Sciences of the Czech Republic and Centre for Cardiovascular \\ Research, Prague, Czech Republic
}

Received March 12, 2008

Accepted May 22, 2008

\begin{abstract}
Summary
The effect of the chronic and acute antioxidant tempol (superoxide dismutase mimetic) treatment on cardiac ischemic tolerance was investigated in adult male Wistar rats. The first experimental group was given tempol $(1 \mathrm{mM})$ in drinking water for three weeks, the second group received tempol $(100 \mathrm{mg} / \mathrm{kg}$, i.v.) $10 \mathrm{~min}$ before test ischemia, and control rats received the same volume of solvent. Anesthetized open-chest animals (pentobarbitone $60 \mathrm{mg} / \mathrm{kg}$, i.p.) were subjected to 20-min coronary artery occlusion and 3-h reperfusion for infarct size determination. Ventricular arrhythmias were monitored during ischemia and at the beginning (5 $\mathrm{min}$ ) of reperfusion. Acute tempol administration shifted the time profile of ischemic arrhythmias to the later phase and significantly increased the number of ischemic and reperfusion premature ventricular complexes, respectively (504 \pm 127 and $84 \pm 21)$ as compared with the chronically treated group (218 \pm 36 and $47 \pm 7$ ) or controls $(197 \pm 26$ and $31 \pm 7)$. Acute tempol-treated rats exhibited a tendency to decrease infarct size $(P=0.087)$. The mechanism of proarrhythmic tempol action during ischemia and reperfusion remains to be elucidated.
\end{abstract}

\section{Key words}

Ischemia/reperfusion • Arrhythmias • Infarction • Oxygen radicals • Tempol

\section{Corresponding author}

J. Neckár, Institute of Physiology, Academy of Sciences of the Czech Republic, Vídeňská 1083, 14220 Prague 4, Czech Republic. E-mail: neckar@biomed.cas.cz
Reactive oxygen species (ROS) play an important role in the pathogenesis of heart ischemia/reperfusion injury. Numerous experimental studies demonstrated that an antioxidant intervention at the beginning of reperfusion reduces all major detrimental manifestations of myocardial infarction (for review see Li and Jackson 2002). In contrast to the clear cardioprotective effect in reperfusion, the impact of chronic treatment or acute administration of antioxidants before coronary artery occlusion still remains controversial. It has been shown that acute or chronic scavenging of ROS had only a minor (if any) effect on myocardial ischemic tolerance (Sebbag et al. 1994, Miura et al. 1988, Andreadau et al. 2004).

Tempol (4-hydroxy-2,2,6,6-tetramethyl-piperidine-N-oxyl) is a stable nitroxide, membrane-permeable, and metal-independent superoxide dismutase (SOD) mimetic. Chronic tempol treatment inhibited progression of ROS-dependent cardiovascular diseases, such as systemic hypertension (Schnackenberg and Wilcox 1999) or pulmonary hypertension (Elmedal et al. 2004) and protected against cardiotoxic effects of some drugs (Zhang et al. 2005). Acute tempol administration at the end of ischemia reduced myocardial infarct size in rats (McDonald et al. 1999). Similarly, tempol given either before or immediately after ischemia decreased the incidence and severity of reperfusion arrhythmias (Guo et al. 2005, Szárszoi et al. 2003). According to our knowledge, the effect of chronic tempol treatment on cardiac ischemic tolerance has not been assessed. The purpose of the present study was to compare effects of tempol administered either in a single dose or chronically before ischemia on myocardial infarction and ventricular 
Table 1. Heart rate and mean arterial blood pressure in controls (Cont), chronically (T-Ch) and acute (T-Ac) tempol-treated animals.

\begin{tabular}{|c|c|c|c|c|}
\hline & Baseline & Pre-ischemic & Ischemia & Reperfusion \\
\hline \multicolumn{5}{|c|}{ Heart rate (beats/min) } \\
\hline Cont & $434.9 \pm 5.9$ & - & $435.2 \pm 3.6$ & $395.3 \pm 7.3^{\mathrm{c}, \mathrm{e}}$ \\
\hline$T-C h$ & $418.8 \pm 8.6$ & - & $416.6 \pm 6.2$ & $378.7 \pm 6.8^{\mathrm{c}, \mathrm{e}}$ \\
\hline$T-A c$ & $422.1 \pm 11.7$ & $361.6 \pm 11.3^{c}$ & $381.3 \pm 12.7^{\mathrm{a}, \mathrm{b}, \mathrm{c}}$ & $404.0 \pm 11.6^{\mathrm{d}}$ \\
\hline \multicolumn{5}{|c|}{ Blood pressure (mmHg) } \\
\hline Cont & $120.8 \pm 3.7$ & - & $125.4 \pm 3.2$ & $96.7 \pm 6.2^{\mathrm{c}, \mathrm{e}}$ \\
\hline$T-C h$ & $103.7 \pm 5.2^{\mathrm{a}}$ & - & $109.5 \pm 5.0^{\mathrm{a}}$ & $88.6 \pm 4.0^{\mathrm{c}, \mathrm{e}}$ \\
\hline$T-A c$ & $119.0 \pm 4.7^{\mathrm{b}}$ & $72.5 \pm 2.3^{c}$ & $92.9 \pm 5.9^{\mathrm{a}, \mathrm{b}, \mathrm{c}, \mathrm{d}}$ & $93.5 \pm 3.5^{\mathrm{c}, \mathrm{d}}$ \\
\hline
\end{tabular}

Values are means \pm S.E.M. from 12 - 15 rats in each group, determined at baseline, after the acute addition of tempol (pre-ischemic), at the end of 20 -min coronary artery occlusion and at the end of the 3 -h reperfusion. ${ }^{\text {a }} P<0.05$ vs. controls; ${ }^{b} P<0.05$ vs. chronically tempol-treated group; ${ }^{\mathrm{c}} P<0.05$ vs. baseline; ${ }^{\mathrm{d}} P<0.05$, vs. pre-ischemic; ${ }^{\mathrm{e}} P<0.05$ vs. ischemia.

arrhythmias in open-chest rats subjected to ischemia/reperfusion.

Susceptibility to ventricular arrhythmias and myocardial infarction was evaluated in anesthetized (sodium pentobarbitone; $60 \mathrm{mg} / \mathrm{kg}$ body weight) openchest pump-ventilated (69 strokes/min, tidal volume of $12 \mathrm{ml} / \mathrm{kg}$ body weight) adult male Wistar rats (250-270 g) subjected to ischemia/reperfusion insult. The first group of animals was given tempol in drinking water $(1 \mathrm{mM})$ for three weeks (T-Ch) before the experiment. Acute tempoltreated animals (T-Ac) received the drug at a dose of 100 $\mathrm{mg} / \mathrm{kg}$ i.v. dissolved in saline $10 \mathrm{~min}$ before ischemia; control animals (Cont), received the same volume of the solvent. A single-lead electrocardiogram (ECG) and blood pressure in the carotid artery were continually recorded. Regional myocardial ischemia was induced by occlusion of the left anterior descendent coronary artery for $20 \mathrm{~min}$, followed by $3-\mathrm{h}$ reperfusion. The number of premature ventricular complexes (PVCs) during ischemia and at the beginning (5 $\mathrm{min}$ ) of reperfusion was counted from ECG records. The area at risk and the infarct area were delineated by staining with potassium permanganate and 2,3,5-triphenyltetrazolium chloride, respectively, and determined by a computerized planimetric method. Detailed description of the experimental procedures and statistical analysis are given elsewhere (Asemu et al. 2000, Neckář et al. 2004).

Chronic tempol treatment did not affect body weight and baseline values of heart rate (HR) but slightly decreased the mean arterial blood pressure (MAP). Acute dose of tempol had strong hemodynamic effects and markedly reduced both variables (Table 1) as compared with the other two groups; these effects persisted during ischemia. HR and MAP values were lower at the end of reperfusion than before ischemia in all groups.

Acute tempol significantly shifted the time profile of arrhythmias to the later phase of ischemia (by about $2 \mathrm{~min}$ ) as demonstrated by the median of PVCs distribution (Fig. 1A). However, the total number of ischemic PVCs was more than doubled in this group $(504 \pm 127)$ as compared with $\mathrm{T}-\mathrm{Ch}$ and Cont groups (218 \pm 36 and $197 \pm 26$, respectively). Similarly, the number of reperfusion PVCs was markedly increased as a consequence of acute tempol administration (Fig. 1B). The number of ischemic and reperfusion arrhythmias did not differ between the control and the chronically tempoltreated group. Acute tempol-treated rats exhibited a tendency to decrease the myocardial infarct size as compared with the controls $(P=0.087$; Fig. $1 C)$; the area at risk normalized to the size of left ventricle did not significantly differ between the groups (29-34\%).

It was shown previously that acute antioxidant treatment before ischemic insult might limit the incidence and severity of ischemic and reperfusion arrhythmias but this issue is still far from a consensus. While preischemic administration of SOD mimetic M40403 or $\mathrm{N}$-acetylcysteine reduced the incidence of ischemic ventricular tachycardia (Masini et al. 2002, Matejíková et al. 2008), Szárzsoi et al. (2001) did not find any antiarrhythmic effect of melatonin during ischemia in isolated perfused hearts. In contrast, we showed an increased number of ischemic ventricular arrhythmias in open-chest rats after acute administration of tempol before coronary artery occlusion. The explanation of the observed proarrhythmic effect is unclear but some possibilities can be considered. First, antioxidants 

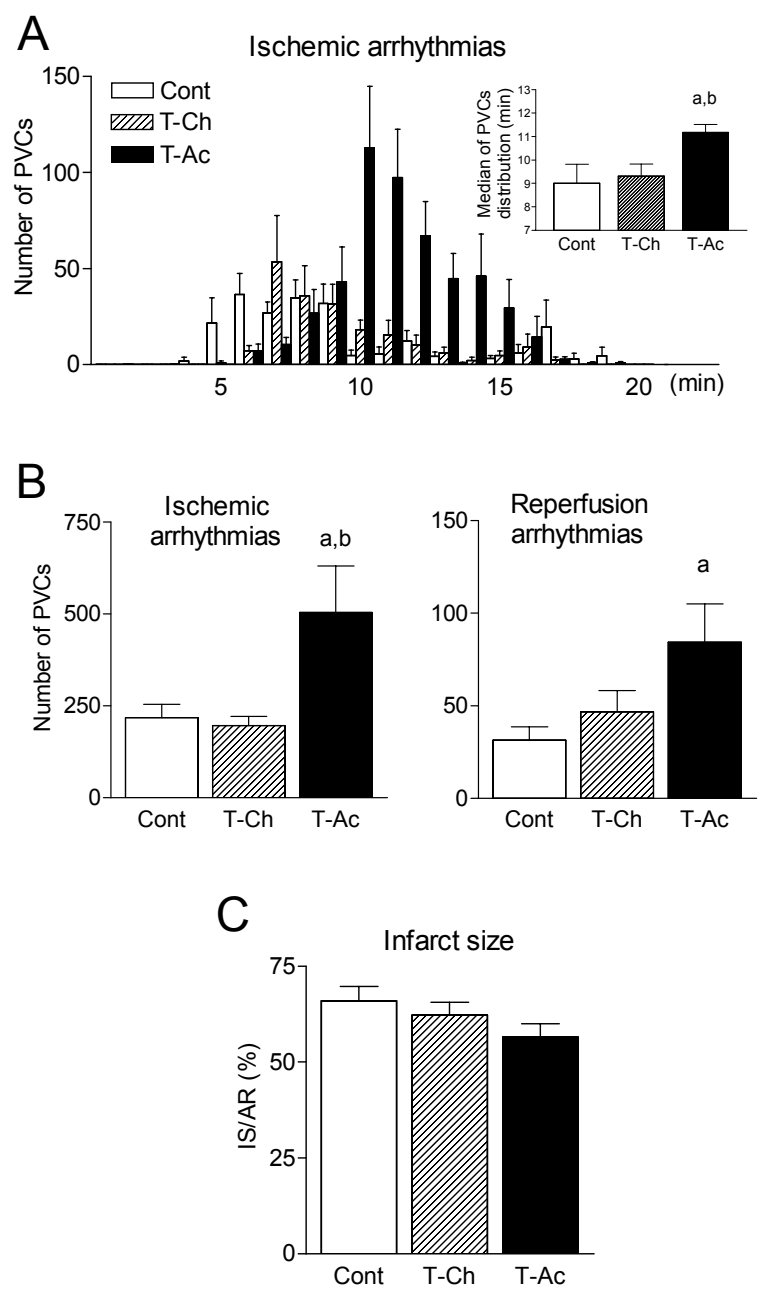

Fig. 1. Distribution of premature ventricular complexes (PVCs) over 20-min coronary artery occlusion (A) and the median of PVC distribution (inset), total number of PVCs during 20-min ischemia (B-left) and at the beginning (5 min) of reperfusion (B-right), and myocardial infarct size expressed as percent of the area at risk (IS/AR; C) in the controls (Cont), acute (T-AC) and chronically (T-Ch) tempol-treated animals. Values are means \pm S.E.M. from $12-15$ rats in each group. ${ }^{\mathrm{a}} P<0.05$ vs. control group; ${ }^{\mathrm{b}} P<0.05$ vs. T-Ch group.

(nitroxides) could act under specific conditions as prooxidative substances increasing membrane instability (Offer et al. 2000, Glebska et al. 2003).

Second, hydrogen peroxide, a superoxide dismutation product, shortens action potential duration (Choi et al. 2005) that may contribute to the formation of reentry arrhythmias. Third, the effect of hydrogen peroxide on action potential shortening is cell typedependent: it is much more pronounced in ventricular myocytes than in Purkinje fibers (Choi et al. 2005). This may increase cardiac membrane heterogeneity leading to ventricular arrhythmias. The detailed electrophysiological investigation of the effects of various antioxidants is required for better understanding the mechanism of tempol-stimulated arrhythmogenesis.

It has been reported that acute tempol administration before short-lasting ischemia $(5 \mathrm{~min})$ markedly reduced the incidence of reperfusion ventricular tachyarrhythmias in open-chest rats (Guo et al. 2005). Our experimental protocol was not primarily designed to study reperfusion arrhythmias as their maximal incidence occurs after less than $20 \mathrm{~min}$ of ischemia (Hearse and Tosaki 1987). In spite of that, we observed increased arrhythmogenesis at reperfusion in acute tempol-treated animals. It is not the only finding indicating that superoxide scavenging before long-lasting ischemia increased the susceptibility to reperfusion arrhythmias. It was reported that SOD administration increased the incidence of ventricular fibrillation after global ischemia (Voogd et al. 1991) and shifted its bell-shaped dependence on the duration of ischemia toward longer ischemia: SOD-treated rats exhibited reperfusion fibrillation even after $30 \mathrm{~min}$ of ischemia in contrast to untreated controls where arrhythmias already disappeared (Koerner and Dage 1990). Similarly, the free radical spin trap DMPO shifted the maximal susceptibility to reperfusion arrhythmias from 10 to $20 \mathrm{~min}$ coronary artery occlusion (Hearse and Tosaki 1987).

In conclusion, our results show that acute (but not chronic) administration of tempol delayed ischemic arrhythmogenesis, probably due to a later onset of cell injury. In spite of that, it increased the number of both ischemic and reperfusion ventricular arrhythmias. The mechanism of this proarrhythmic action of tempol remains to be clarified.

\section{Conflict of Interest}

There is no conflict of interest.

\section{Acknowledgements}

The authors thank Mrs. Milana Pešková for technical assistance. This study was supported by research grants GACR 305/06/P372, GACR 305/07/0875.

\section{References}

ANDREADAU I, ILIODROMITIS EK, MIKROS E, BOFILIS E, ZOGA A, CONSTANTINOU M, TSANTILIKAKOULIDOU A, KREMASTINOS DT: Melatonin does not prevent the protection of ischemic preconditioning in vivo despite its antioxidant effect against oxidative stress. Free Radic Biol Med 37: 500-510, 2004. 
ASEMU G, NECKÁŘ J, SZÁRSZOI O, PAPOUŠEK F, OŠŤÁDAL B, KOLÁŘ F: Effects of adaptation to intermittent high altitude hypoxia on ischemic ventricular arrhythmias in rats. Physiol Res 49: 597-606, 2000.

CHOI BH, HA K-C, PARK J-A, JUNG Y-J, KIM J-C, LEE G-I, CHOI H-S, KANG Y-J, CHAE S-W, KWAK Y-G: Regional differences of superoxide dismutasee activity enhance the superoxide-induced electrical heterogeneity in rabbits hearts. Basic Res Cardiol 100: 355-364, 2005.

ELMEDAL B, DE DAM MY, MULVANY MJ, SIMONSEN U: The superoxide dismutase mimetic, tempol, blunts right ventricular hypertrophy in chronic hypoxic rats. Br J Pharmacol 141: 105-113, 2004.

GLEBSKA J, SKOLIMOWSKI J, KUDZIN Z, GWOZDZINSKI K, GRZELAK A, BARTOSZ G: Pro-oxidative activity of nitroxides in their reaction with glutathione. Radic Biol Med 35: 310-316, 2003.

GUO R, GAO X-Y, WANG W, WANG H-J, ZHANG Y, ZHU G-Q: Tempol reduces reperfusion-induced arrhythmias in anaesthetized rats. Pharmacol Res 52: 192-198, 2005.

HEARSE DJ, TOSAKI A: Reperfusion-induced arrhythmias and free radicals: studies in the rat heart with DMPO. J Cardiovasc Pharmacol 9: 641-650, 1987.

KOERNER JE, DAGE RC: Delay of occurrence of reperfusion-induced ventricular fibrillation in the isolated rat heart with superoxide dismutase. J Cardiovasc Pharmacol 16: 461-467, 1990.

LI C, JACKSON RM: Reactive species mechanisms of cellular hypoxia-reoxygenation injury. Am J Physiol 282: C227C241, 2002.

MASINI E, CUZZOCREA S, MAZZON C, MARZOCCA C, MANNAIONI PF, SALVEMINI D: Protective effects of M40403, a selective superoxide dismutase mimetic, in myocardial ischemia and reperfusion in vivo. $\mathrm{Br} J$ Pharmacol 136: 905-917, 2002.

MATEJIKKOVÁ J, KUCHARSKÁ J, PINTÉROVÁ M, PANCZA D, RAVINGEROVÁ T: Protection against ischaemiainduced ventricular arrhythmias and myocardial dysfunction conferred by preconditioning in the rat heart: Involvement of mitochondrial $\mathrm{K}_{\mathrm{ATP}}$ channels and reactive oxygen species. Physiol Res 2008 (in press).

MCDONALD MC, ZACHAROWSKI K, BOWES J, CUZZOCREA S, THIEMERMANN C: Tempol reduces infarct size in rodent models of regional myocardial ischemia and reperfusion. Free Radic Biol Med 27: 493-503, 1999.

MASINI E, CUZZOCREA S, MAZZON C, MARZOCCA C, MANNAIONI PF, SALVEMINI D: Protective effects of M40403, a selective superoxide dismutase mimetic, in myocardial ischemia and reperfusion in vivo. $\mathrm{Br} J$ Pharmacol 136: 905-917, 2002.

MIURA T, DOWNEY JM, HOTTA D, IIMURA O: Effect of superoxide dismutase plus catalase on myocardial infarct size in rabbits. Can J Cardiol 4: 407-411, 1988.

NECKÁŘ J, OŠŤÁDAL B, KOLÁŘ F: Myocardial infarct size-limiting effect of chronic hypoxia persists for five weeks of normoxic recovery. Physiol Res 53: 621-628, 2004.

OFFER T, RUSSO A, SAMUNI A: The pro-oxidative activity of SOD and nitroxide SOD mimics. FASEB $J$ 14: 1215$1223,2000$.

SEBBAG L, FORRAT R, CANET E, RENAUD S, DELAYE J, DE LORGERIL M: Effects of dietary supplementation with alpha-tocopherol on myocardial infarct size and ventricular arrhythmias in a dog model of ischemiareperfusion. J Am Coll Cardiol 24: 1580-1585, 1994.

SCHNACKENBERG CG, WILCOX CS: Two-week administration of tempol attenuates both hypertension and renal excretion of 8-Iso prostaglandin $\mathrm{F}_{2 \alpha}$. Hypertension 33: 424-428, 1999.

SZÁRSZOI O, ASEMU G, VANĚČEK J, OŠŤÁDAL B, KOLÁŘ F: Effect of melatonin on ischemia and reperfusion injury of the rat heart. Cardiovasc Drugs Ther 15: 251-257, 2001.

SZÁRSZOI O, ASEMU G, OŠŤÁDAL B, KOLÁŘ F: The role of reactive oxygen species and nitric oxide in ischemia/reperfusion injury of chronically hypoxic rat hearts. Eur J Heart Fail 2 (Suppl): 53, 2003.

VOOGD A, SLUITER W, KOSTER JF: Contradictory effects of superoxide dismutase after global or regional ischemia in isolated rat hearts. Free Radic Biol Med 11: 71-75, 1991.

ZHANG G-X, KIMURA S, NISHIYAMA A, SHOKOJI T, RAHMAN M, YAO L, NAGAI Y, FUJISAWA Y, MIYATAKE A, ABE Y: Cardiac oxidative stress in acute and chronic isoproterenol-infused rats. Cardiovasc Res 65: 230-238, 2005. 